\title{
Laparoscopic Removal of Abdominal Cerclage and Vaginal Delivery at 21 Weeks
}

\author{
Alex Ades, MD, PhD, Kim C. Dobromilsky, BMBS, BPharm \\ AGORA Centre for Women's Health, Epworth Hospital, Melbourne, Victoria, Australia (both authors).
}

\begin{abstract}
Introduction: Transabdominal cerclage (TAC) is a procedure for cervical insufficiency in women in whom transvaginal cerclage cannot be performed. In recent years, laparoscopic transabdominal cerclage has gained favor by eliminating the need for laparotomy and reducing surgical morbidity.
\end{abstract}

Case Description: We present a case of laparoscopic removal of a TAC in a 27-year-old woman with uterus didelphys, who presented with fetal death in utero at 21 weeks 3 days.

Conclusion: This successful, minimally invasive technique eliminated the need for hysterotomy and the potential corresponding morbidity associated with the operation and allowed for normal spontaneous vaginal delivery.

Key Words: Hysterotomy, Transabdominal cerclage, Transvaginal cerclage, Uterine malformation, Uterus didelphys.

Citation Ades A, Dobromilsky KC. Laparoscopic removal of abdominal cerclage and vaginal delivery at 21 weeks. CRSLS e2014.00247. DOI: 10.4293/CRSLS.2014.00247.

Copyright $\odot 2015$ by SLS, Society of Laparoendoscopic Surgeons. This is an open-access article distributed under the terms of the Creative Commons Attribution-Noncommercial-ShareAlike 3.0 Unported license, which permits unrestricted noncommercial use, distribution, and reproduction in any medium, provided the original author and source are credited.

Address correspondence to: Kim C. Dobromilsky, BM, BS, AGORA Centre for Women's Health, Epworth Hospital, Melbourne, Victoria, Australia. Tel: +61-3-94212533, Fax +61-3-9429-7407, E-mail: kim@dobro.net.au

\section{INTRODUCTION}

Transabdominal cerclage (TAC) has been described as a treatment for cervical insufficiency in women who cannot have the transvaginal procedure, the most common reasons being previous cervical surgery leaving insufficient cervical tissue in the vagina, congenital uterine malformation, and failed previous transvaginal cerclage (TVC). ${ }^{1,2}$

In recent years, several series of laparoscopically placed TAC have been published. ${ }^{3,4}$ The procedure has produced success rates and obstetric outcomes similar to those obtained when the TAC is placed via laparotomy, but with reduced surgical morbidity. Both have significantly improved outcomes when compared with transvaginal cerclage in high-risk women. ${ }^{5,6}$ Laparoscopic TAC is placed either before pregnancy or early in gestation, once fetal viability has been confirmed on ultrasound. The disadvantage of TAC is that it is not removed at delivery, and the fetus must be delivered by cesarean section.

An obstetric complication resulting in fetal demise in the second trimester would require a hysterotomy, usually with a midline uterine incision, to remove the fetus. This procedure carries significant surgical morbidity with possible long-term complications and negative implications for future pregnancies.

The association between congenital uterine malformation and obstetric complication has long been recognized. Uterine malformation is common, with a mean prevalence in fertile patients of $4.3 \% .^{7}$ Most women with these malformations have no problems with pregnancy. Uterus didelphys is a specific type of uterine malformation that has an estimated incidence of $8.4 \%$ of all uterine malformations. ${ }^{7}$ If untreated, it is associated with an approximate 30\% miscarriage and a 30\% preterm delivery rate. ${ }^{7}$ Several studies show improvement in preterm delivery rate with the placement of a cervical cerclage in patients with uterine abnormalities. ${ }^{8-10}$ In 1 of these studies, improvement was not observed after placement of the cerclage, except in the setting of diagnosed cervical insufficiency. ${ }^{8}$ However, in another 2 studies there was a reduction in the preterm delivery rate, regardless of whether cervical insufficiency had been diagnosed. ${ }^{9,10}$ All of these studies included patients with uterus didelphys. ${ }^{8-10}$ 


\section{CASE REPORT}

The patient is a 27 -year-old woman, gravida 3 para 2 , with no living children, who was known to have uterus didelphys, with 2 cervices and a partial longitudinal vaginal septum. She had a history of 2 midtrimester fetal losses attributed to cervical insufficiency. Both of these pregnancies were in the left uterus. The first pregnancy resulted in a stillbirth at 20 weeks' gestation after the patient presented to the hospital with painless dilatation of the cervix and bulging membranes. During the second pregnancy, an elective TVC was inserted at 13 weeks' gestation. Despite this, preterm labor occurred, and the fetus was delivered at 24 weeks, which resulted in neonatal demise at 10 days of age. After the second midtrimester delivery, the patient was referred for laparoscopic placement of a TAC, indicated by the diagnosis of cervical insufficiency and failed TVC. She had undergone a laparoscopic procedure in mid-2013 in which 2 separate stitches were placed at the level of the isthmus around each cervix (Figure 1). Six months after the operation, the patient achieved spontaneous pregnancy, this time in the right uterus. Routine antenatal test results were normal, and screening for aneuploidies showed low risk. Successive ultrasounds every 4 weeks revealed a consistently long, closed cervix. A routine ultrasound for fetal morphology at 21 weeks revealed fetal death in utero. Instead of a laparotomy with hysterotomy to deliver the fetus, the patient was offered a laparoscopy for removal of the right cervical cerclage to allow for vaginal delivery.

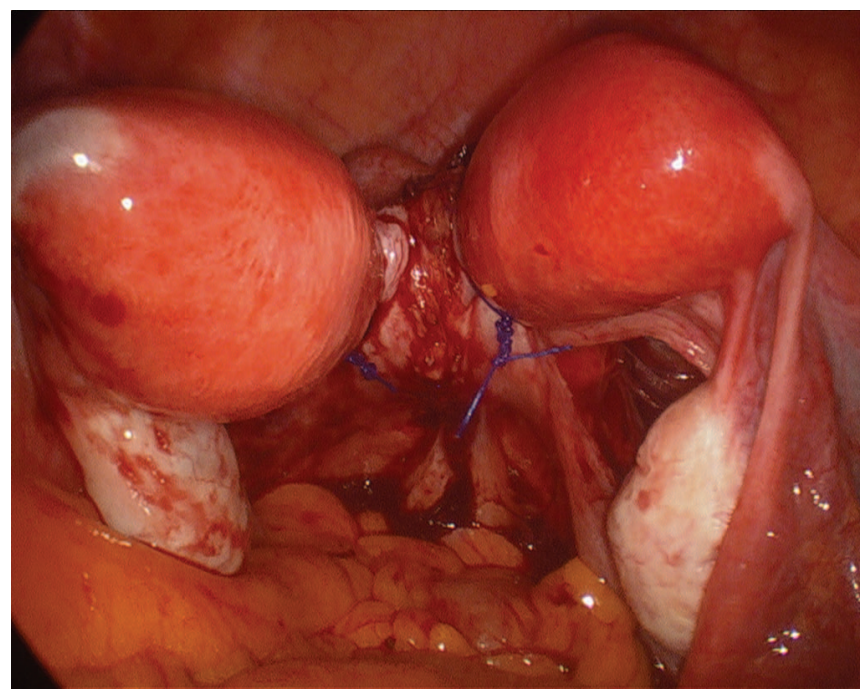

Figure 1. Cerclages placed at the level of the cervical isthmus, tied posteriorly
Approximately 14 hours after successful laparoscopic removal of the cerclage from the right cervix, the patient progressed to spontaneous vaginal delivery of a partially macerated fetus consistent with 21 weeks' gestation. Manual removal of the retained placenta under general anaesthetic was necessary. There were no complications with the laparoscopy or the delivery, and the patient was discharged the following day. Postmortem examination showed a normally formed fetus with hypoxia due to placental insufficiency as the probable cause of death.

\section{Surgical Procedure For Removal of the TAC}

The patient was placed in the lithotomy position while under general anaesthesia. The camera port was placed 2 $\mathrm{cm}$ above the umbilicus in the midline through direct visual entry (Kii Fios First Entry Systems, Applied Medical Resources, Rancho Santa Margarita, California). This site was chosen instead of the usual umbilical incision because of the size of the pregnant uterus. Three $5-\mathrm{mm}$ accessory ports were inserted under vision in both iliac fossae and suprapubically. A $30^{\circ}$ laparoscope was used to facilitate visualization of the anterior aspect of the uterus and uterovesical junction.

The cervical cerclage had been tied posteriorly with 1 Prolene suture (dyed polypropylene suture; Ethicon, Somerville, New Jersey), but we were not able to access the pouch of Douglas, as the pregnant uterus filled the entire pelvis and could not be displaced anteriorly.

The peritoneum was incised at the uterovesical junction, and the uterovesical space was carefully dissected with scissors and monopolar diathermy toward the cervicoisthmic region where the suture had been placed. The region was extremely vascular, as expected in the pregnant state.

Caution was necessary when moving the instruments so as not to apply any pressure to the gravid uterus, and therefore the instruments were introduced and moved forward very carefully under vision from all accessory ports around this large obstacle.

Once the suture was visualized, it was grasped, elevated, and cut with scissors. Intraoperative blood loss was minimal.

\section{DISCUSSION}

One of the disadvantages of the TAC is the need for a cesarean section to deliver the fetus. A hysterotomy performed during the second trimester for a fetus that will not survive carries significant surgical morbidity as well as 
possible long-term complications and negative implications for future pregnancies. It was not the objective of this report to discuss the surgical morbidity or complications of a midtrimester hysterotomy nor the psychological implications for the patient.

Our patient experienced reduced discomfort and a prompt recovery after removal of the TAC. There should be no major obstacles to a future pregnancy, even in patients who require the laparoscopic placement of another TAC.

Articles previously published in this journal by Carter et al ${ }^{11,12}$ have provided an explanation of techniques for laparoscopic removal of the TAC in gestations up to 19 weeks. The technique we describe provides additional useful information for the undertaking of operative laparoscopy in pregnancy beyond 20 weeks' gestation. The use of an angled $30^{\circ}$ laparoscope was very helpful for visualizing the anterior cervical isthmus.

The patient must undergo a repeat laparoscopy to insert a new TAC before the next pregnancy. This approach carries lower surgical risks and morbidity than the aforementioned hysterotomy.

Advanced laparoscopic surgical skills and a well-trained surgical team are necessary both for the initial laparoscopic placement of the TAC and for its removal during pregnancy.

\section{CONCLUSION}

Laparoscopic removal of a cervical TAC is feasible beyond 20 weeks of pregnancy. In this case, it avoided the need for a second trimester hysterotomy to deliver a dead fetus.

The outcome in this case should give patients and doctors peace of mind when deciding whether to undertake a TAC for treatment of high-risk cases of cervical insufficiency.

\section{References:}

1. Novy MJ. Transabdominal cervicoisthmic cerclage: a reappraisal 25 years after introduction. Am J Obstet Gynecol. 1991; 164:1635-1642.

2. Cammarano CL, Herron MA, Parer JT. Validity of indications for transabdominal cerclage for cervical incompetence. Am J Obstet Gynecol. 1995;172:1871-1875.

3. Whittle WL, Singh SS, Allen L, et al. Laparoscopic cervicoisthmic cerclage: surgical technique and obstetric outcomes. $A m \mathrm{~J}$ Obstet Gynecol. 2009;201:364.e1-e7.

4. Carter JF, Soper DE, Goetzl LM, Van Dorsten JP. Abdominal cerclage for the treatment of recurrent cervical insufficiency: laparoscopy or laparotomy? Am J Obstet Gynecol. 2009;201: 111.e1-e4.

5. Tusheva OA, Cohen SL, McElrath TF, Einarsson JI. Laparoscopic placement of cervical cerclage. Rev Obstet Gynecol. 2012; 5:e158-e165.

6. Burger NB, Brolmann HA, Einarsson JI, et al. Effectiveness of abdominal cerclage placed via laparotomy or laparoscopy: systematic review. J Minim Invas Gynecol. 2011;18:696-704.

7. Grimbizis GF, Camus M, Tarlatzis BC, et al. Clinical implications of uterine malformations and hysteroscopic treatment results. Hum Reprod Update. 2001;7:161-174.

8. Leibovitz Z, Levitan Z, Aharoni A, Sharf M. Cervical cerclage in uterine malformations. Int J Fertil. 1992;37:214-217.

9. Ben-Rafael Z, Seidman DS, Recabi K, et al. Uterine anomalies: a retrospective, matched-control study. J Reprod Med. 1991; 36:723-727.

10. Golan A, Langer R, Neuman M, et al. Obstetric outcome in women with congenital uterine malformations. I Reprod Med. 1992;37:233-236.

11. Carter JF, Savage A, Soper DE. Laparoscopic removal of abdominal cerclage at 19 weeks' gestation. JSLS. 2013;17:161163.

12. Carter JF, Soper DE. Laparoscopic removal of abdominal cerclage: a case report. JSLS. 2007;11:375-377. 